\title{
The Weight Analysis and Calculation about Factors of Passenger Sat- isfaction
}

\author{
Y. LIU \\ Traffic and Transportation School, Beijing Jiaotong University, Beijing, China
}

\begin{abstract}
KEYWORD: Urban Traffic; Passenger Satisfaction Evaluation; Assessment System; Compound Attribute; Combination Weighting Method

ABSTRACT: Firstly, the metro passenger satisfaction evaluation index system was established based on the real process of a single passenger, such as arriving, security checking, buying tickets and transiting. Secondly, the passenger travel satisfaction evaluation questionnaire was designed to conduct investigations and analysis was made on reliability and validity. Thirdly, on the principle of market segmentation, the passengers were divided into 6 categories from double-attribute angle of the travel purpose and the monthly income. Then the weight preference was determined by the specific weighting methods combining subjection and objection. The weight preference of the six kinds of passengers for each factor affecting passenger travel satisfaction were calculated and compared. Finally, according to different weight preference for different affecting factors, the personalized service marketing strategy was put forward for different kinds of passengers.
\end{abstract}

\section{INTRODUCTION AND OVERVIEW}

\section{Background}

Passengers' travel demands in urban rail transit have characteristics of diversification and differentiation. The research on passengers' satisfaction, is the key support to understand passengers' travel demands and to assess the service quality of rail transport operators, to help them improve service quality and achieve the optimal allocation of resources. The evaluation problem about urban rail transit passengers' satisfaction is actually making research on influencing factors of satisfaction. Firstly, get passengers' experience during their travel process, then establish the evaluation index system, in order to analyze and calculate the weight assigned on different influencing factors.

\section{Literature review}

Researches on the passengers' satisfaction about urban rail transit at home and abroad are mostly focused on the establishment of the evaluation index system. Efficiency, convenience, comfort, fees, security, cleanliness and service management are proposed as the evaluation indicators on passengers' satisfaction. ${ }^{[1]}$ According to American customer satisfaction index model (ASCI) ${ }^{[2,3]}$, perceived quality can be divided into punctual \& efficient, clean \& comfortable, order \& security, equipment \& facilities, station \& train environment and service management. Structural equation model $^{[4,5]}$ is adopted to make customer satisfaction as the reflecting latent variable, and make economic, comfort, convenience and punctuality as interpreting latent variables and set convenient transfer, ticket price and purchasing convenience, traffic accidence, running interval, punctuality as observed variables.

\section{SURVEY DESIGN}

\section{Evaluation system of passengers' satisfaction}

This paper describes the influencing factors about passengers' satisfaction from five aspects, such as comfort, safety, and thoughtful service, convenience and economy. And evaluation indexes are designed according to passenger's travel links. 
Table1. Evaluation Index System

\begin{tabular}{lcc}
\hline First-grade Index & Second-grade Index \\
\hline & Congestion on stairs(Com1) \\
& Congestion on escalator(Com2) \\
Congestion in passageways(Com3) & Congestion on platform(Com4) \\
Comfort (Com) & Congestion in car(Com5) \\
& & Station environment(temperature, ventila- \\
& tion)(Com6)
\end{tabular}

Reliability and validity analysis

366 questionnaires are conducted, and 330 valid questionnaires are received, which means effective recovery rate is $92.31 \%$. To determine and analyze the stability and reliability of data, SPSS software are used to make reliability analysis and Alpha models are used to get Chronbach's Alpha value of each influencing factors (see table 3 ).

Table 3 Reliability Test

\begin{tabular}{lll}
\hline Dimensions & number & Chronbach's Alpha \\
\hline Comfort & 6 & 0.842 \\
Security & 1 & - \\
Service & 3 & 0.873 \\
Convenience & 7 & 0.861 \\
Economy & 1 & - \\
Overall Satisfaction & 18 & 0.855 \\
\hline
\end{tabular}

According to table 3 , Alpha coefficients for all indicators are greater than 0.8 , indicating that passenger travel satisfaction surveys have a high confidence level, which means research results have good consistency and stability.

To test whether the contents of the questionnaire is consistent with survey objectives, SPSS software was applied to do KMO and Bartlet test and validity test results about factors which are shown in Table 3.

Table 4 Validity Test

\begin{tabular}{lll}
\hline Kaiser-Meyer-Olkin Measure of Sampling Adequacy. & 0.734 \\
\hline \multirow{2}{*}{ Bartlett's Test of Sphericity } & Approx. Chi-Square & 656.076 \\
& Sig. & 0.00 \\
\hline
\end{tabular}


According to table 4, value of KMO test is 0.734 , and the confidence level of Bartlett test was significantly lower than 0.05 , indicating that the questionnaires are reliable and can be used for further analysis.

\section{METHOD OF CALCULATING WEIGHT OF INFLUENCING FACTORS}

\section{Principle}

In order to fully reflect the subjective and objective information, an optimal combination weighting method based on the linear weighting method is given. In this method, the subjective weights and objective weights are combined together, and the weighted coefficients can be calculated by the mathematical programming model, which can reflect the subjective and objective information.

Notation

In this section, we provide notations that are used throughout the paper. This is followed $b$ $\mathrm{y}$ the key concepts associated with the research.

Procedures

Step1: Suppose that $\alpha_{j}$ is the score which passenger $p$ evaluate the index $j$, subjective weight is calculated.

$$
\begin{aligned}
& \alpha_{j}=\sum_{p=1}^{m} a_{j}^{p} \\
& w_{j}^{\prime}=\alpha_{j} / \sum_{j=1}^{n} \alpha_{j}
\end{aligned}
$$

Step2: The Kendall's Tau-b coefficient $\tau$ is adopted to describe correlation between indexes, and objective weight based on correlation coefficient can be calculated as follows.

$$
\begin{aligned}
\tau_{b j} & =\frac{n_{s j}-n_{d j}}{\sqrt{\left(n_{s j}+n_{d j}+T_{x}\right)\left(n_{s j}+n_{d j}+T_{y}\right)}} \\
w_{j}^{1} & =\tau_{b j} / \sum_{j=1}^{n} \tau_{b j}
\end{aligned}
$$

Step3: Suppose $r_{i j}$ is the score which passenger $i$ evaluate on the index $j$, objective weight can be calculated.

$$
\begin{aligned}
& R=\left[\begin{array}{cccc}
r_{11} & r_{12} & \ldots & r_{1 n} \\
r_{21} & r_{22} & \ldots & r_{2 n} \\
\ldots & \ldots & \ldots & \ldots \\
r_{m 1} & r_{m 1} & \ldots & r_{m 1}
\end{array}\right]_{m \times n} \\
& f_{i j}=r_{i j} / \sum_{i=1}^{m} r_{i j} \\
& H_{i}=-\frac{1}{\ln (m)} * \sum_{i=1}^{m} f_{i j} * \ln \left(f_{i j}\right) \\
& w_{j}^{2}=\left(1-H_{j}\right) / \sum_{j=1}^{n}\left(1-H_{j}\right) \\
& w_{j}^{\prime \prime}=w_{j}^{1} *\left(100-w_{j}^{2}\right) / \sum_{j=1}^{n} w_{j}^{1} *\left(100-w_{j}^{2}\right)
\end{aligned}
$$

Step4: Combined weighting method

As we can see in the formula (10), the subjective weight which passenger $i$ evaluate upon index $j$ is $r_{i j} \alpha w_{j}^{\prime}$, while the objective weight is $r_{i j} \beta w_{j}^{\prime \prime}$. And the difference between them is $r_{i j} \alpha w_{j}^{\prime}-r_{i j} \beta w_{j}^{\prime \prime}$. The smaller the deviate degree $d_{i}$ is, the more consistent the subject information and object information are. ${ }^{[6]}$ 


$$
\begin{aligned}
& \operatorname{minZ}=\sum_{i=1}^{m} d_{i}=\sum_{i=1}^{m} \sum_{j=1}^{n}\left(r_{i j} \alpha w_{j}^{\prime}-r_{i j} \beta w_{j}^{\prime \prime}\right)^{2} \\
& \alpha=\sum_{i=1}^{m} \sum_{j=1}^{n} r_{i j}^{2} w_{j}^{\prime \prime} / \sum_{j=1}^{m} \sum_{i=1}^{n} r_{i j}^{2}\left(w_{j}^{\prime}+w_{j}^{\prime \prime}\right)^{2} \\
& \beta=\sum_{i=1}^{m} \sum_{j=1}^{n} r_{i j}^{2} w_{j}^{\prime} / \sum_{i=1}^{m} \sum_{j=1}^{n} r_{i j}^{2}\left(w_{j}^{\prime}+w_{j}^{\prime \prime}\right)^{2} \\
& w=\alpha w_{j}^{\prime}+\beta w_{j}^{\prime \prime}, \alpha+\beta=1, \alpha, \beta \geq 0
\end{aligned}
$$

\section{A CASE STUDY: THE BEIJING METR}

\section{Passengers division based on compound attributes}

If passengers are divided in accordance with the single attribute, the diversity of travel demand can't be accurately described. Therefore, monthly income and travel purposes are adopted in the paper as the criteria to classify passengers who are divided into 6 categories.

Table 5 Passenger Attributes

\begin{tabular}{ll}
\hline FID & Passenger Type \\
\hline 1 & Commuter - low income \\
2 & Commuter - middle income \\
3 & Commuter - high income \\
4 & Leisure - low income \\
5 & Leisure - middle income \\
6 & Leisure - high income \\
\hline
\end{tabular}

\section{Calculation and comparison of weight}

Application written by Java is used to calculate the comprehensive weight of six types of passengers for factors influencing their travel satisfaction. The result is represented in figure 1.

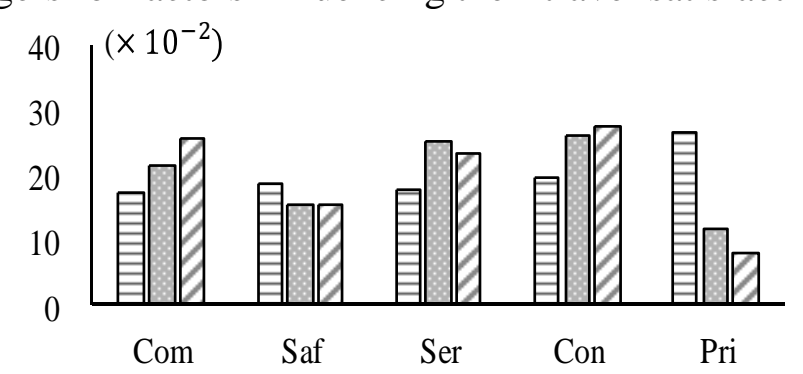

घlow-income $\square$ middle-income $\square$ high-income

a) The Weight Preferences of commuters

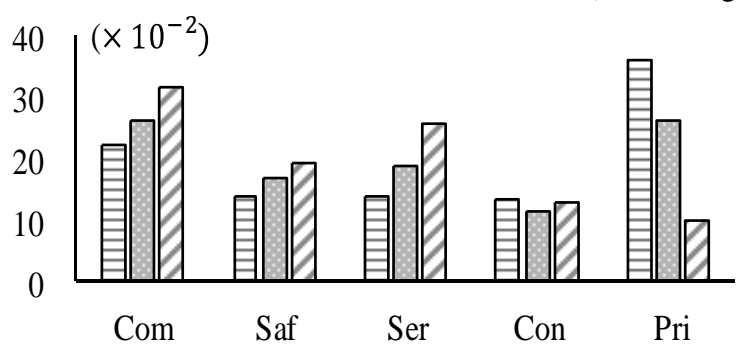

日low-income $\square$ middle-income $\square$ high-income

b) The Weight Preferences of Leisure Passengers

Fig. 1 the Contrast Diagram of the Weight for Primary Factors

After comparison about the weight preferences, some results are gotten as follows:

The factor which catches the most attention of all types of passengers is comfort. Convenience and economy are also concerned, but vary from different passengers. The weight preference of safety ranks the middle, and different types of passengers have the same mind, which is relatively stable. 
The weight preferences of passengers for eighteen secondary indicators can be seen in figure 2 .
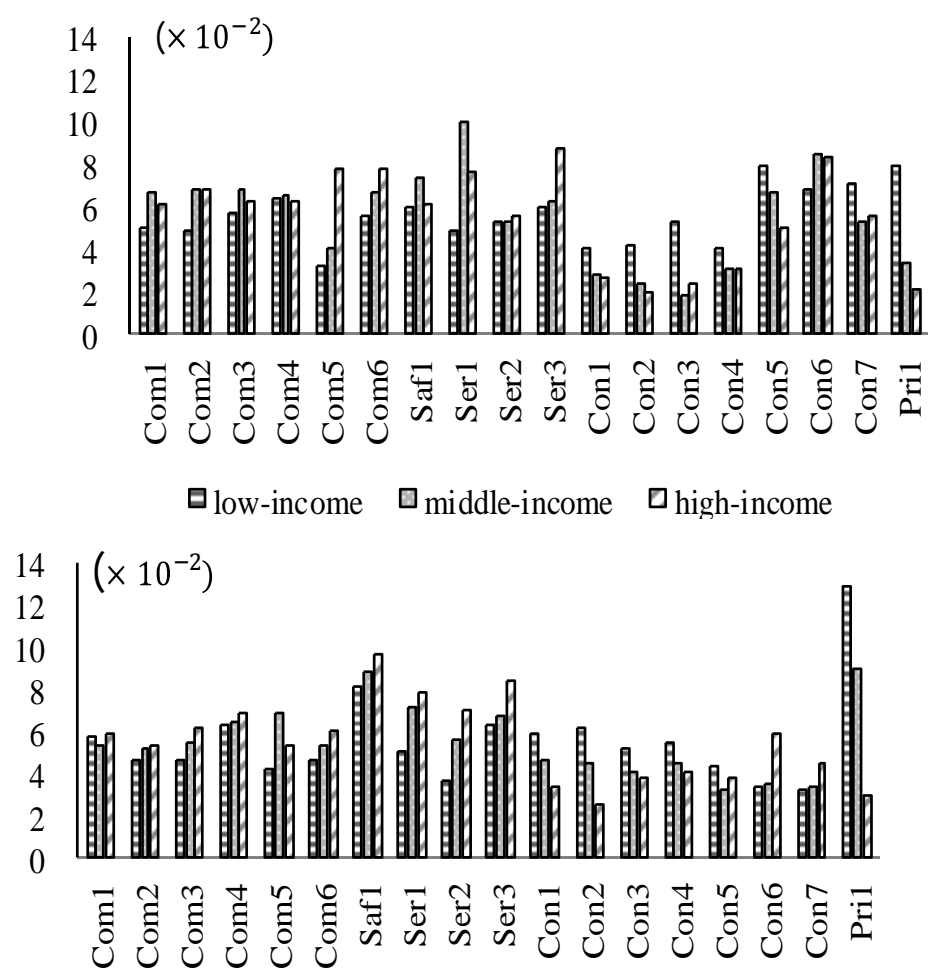

日low-income $\square$ middle-income $\square$ high-income $\quad$ b) The Weight Preferences of Leisure Passengers
Fig.2 the Contrast Diagram of the Weight for Secondary Factors

According to figure 2, we have come to the conclusion as follows:

(1) Commuters are more concerned about waiting time on platform, service attitude, information service, station environment, queue time while limitation, order, congestion on platform, congestion on escalator and transfer time.

(2) Leisure passengers are more concerned about order, ticket price, information service, service attitude, congestion on platform, congestion on stairs, congestion in passageways, congestion in car, guiding sign and station environment.

Taking some comparative analysis from the perspective of income, low-income passengers are more concerned about ticket price, particularly low-income passengers who travel on purpose of tourism or shopping are sensitive to the ticket price. Middle-income passengers are more concerned about service attitude of staff, especially high-income passengers who travel on purpose of office or school are more concerned about information service and order.

Merged analysis about passenger type based on the weight preference

By analyzing the weight preferences of passengers on different influencing factors, six types of passengers are merged into three different categories: efficiency, economy and leisure.

Efficient passengers emphasize on "speed + convenient + time" mainly for the purpose of achieving rapid movement, who are composed of commuters who are middle-income or highincome. Economic passengers are more sensitive to ticket prices and prefer to the travel mode "economy + convenience". These passengers mainly consist of commuters who are low-income and leisure passengers who are low-income. Casual passengers who are composed of leisure passengers with middle or high income pay more attention to the feeling of pleasure in travel and prefer to "comfort + convenience + service".

Metro operators can develop and provide personalized service to passengers based on the analysis on the travel preferences of different categories of passengers. For example, aimed at improve efficient passengers' satisfaction, operators can short the interval between two trains during peak hours or reduce the time of security checking and ticket by increasing ticket vending machines. And some reasonable fare discount can be launched for economic passenger. Some measures such as limitation in station gate or increasing the number of trains to decrease the capacity rate of train, 
thus providing passengers with more clean environment and better service, in order to improve casual passengers' satisfaction.

\section{CONCLUSION}

Comparing the weight preference of passengers for each link in their trip, all the passengers are concerned about convenience during their trip. Comfort, safety and service are also paid attention to by all types of passengers. But passengers' satisfaction varies from their characters. Some results by comparing different groups of passengers are as follows:

(1) Commuters are more concerned about convenience, comfort, economy and service. And the higher their income are the more concerned they are about comfort. When it comes to convenience indicator, commuters are less concerned about the links in their trips such as security checking, ticket and gate, and more concerned about limiting, waiting on platform and transfer.

(2) Leisure passengers are more concerned about comfort, economy and service. Low-income and middle-income groups are more concerned about ticket price and order, high-income groups pay more attention to information services and attitude of staff, but less attention to ticket price.

Metro operators can classify passenger into three categories according to travel preferences of passengers, which are incorporated into efficient passengers, economic passengers and casual passengers. Therefore some targeted and personalized service can be elaborated respectively according to their travel modes.

\section{REFERENCE}

[1] ZHOU Y F, ZHOU L S. Establishing Assessment System about Passenger Satisfaction Indices in Urban Rail Transit [J]. Urban Rapid Rail TRANSIT, 2007, 20(5): 25-28.

[2] ZHANG H H. Evaluation of Service Quality for Urban Rail Transit based on Passenger Satisfaction [D]. Bejing Jiaotong University, 2009.

[3] XIAO J, LI F. Assessment on Passengers' Satisfaction about Urban Rail

Transit Based on PLS[J]. Urban Transit Research, 2011, 14(7): 56-59.

[4] DAI Z H, LI Z J, The Passenger Satisfaction Evaluation for Urban Rail

Traffic Based on Bayesian Network [J]. Technology \& Economy in Areas of Communications, 2012, 14(4): 119-122.

[5] CAI Y, Improvement strategies to enhance passenger satisfaction the quality of Beijing Subway service[D], University of International Business and Economics, 2014

[6] ZHOU H R, Fuzzy comprehensive evaluation of group decision making based on entropy weight method [J]. Statistics \& Decision, 2008, 08: 34-36. 